\title{
Workplace Wellbeing On Maungataturi Mountain: The Connection Between Ecological Restoration And Workplace Happiness
}

Maree Roche, Waikato Institute of Technology, New Zealand

Carollyn Rolley, Waikato Institute of Technology, New Zealand

\begin{abstract}
This study reports on findings from the restoration of Maungatautari Ecological Island Reserve, New Zealand. Twenty-one farming workplaces were affected by the restoration process. Findings highlight how an enhanced workplace context, via the restoration process, aided individual wellbeing in terms of developing meaning and social connectivity in previously isolated work places. The findings lend support to the notion that human resource academics and practitioners may find the contributions of positive psychology aid in enhancing meaning and social connectivity at work, leveraging workplace and employee potential and wellbeing.
\end{abstract}

Keywords: Wellbeing; positive psychology; farming workplaces; connection to place; meaning; social connectivity

\section{INTRODUCTION}

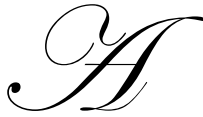

ristotle, over 2000 years ago, argued that happiness was the key to a good life. Happiness however was not about the immediate joys of money or pleasure, but the role and contribution to greater positive factors in life, those that aid individuals in finding purpose and meaning. Further, the early Greek philosopher argued that happiness was not separate or exclusionary to self, or distance from other selves, but is sought in the environment in which we live. "Happiness' therefore is a holistic ideal; it depends both on the individual factors that aid our own happiness and on the environment in which we live out our lives (Devettere 2002).

In modern life much of our time is spent in the workplace. In the modern world therefore, to be happy, people need to not only to find purpose and meaning but also to work in organisations that develop and recognize the contribution of work and workplaces on individual happiness (Gavin and Mason 2004).

\section{ACCENTUATE THE POSITIVE}

Historically, the organisational sciences have been preoccupied with the negative aspects of work and life (Wright and Quick 2009 a,b); studies have highlighted and demonstrated, for example, the unfavourable outcome of stress and conflict on work and life, on wellbeing, job satisfaction, turnover intentions and commitment (Haar 2006; Kossek and Ozeki 1998, 1999; Thompson, Beauvais, and Lyness, 1999; Eaton 2003). Luthans, Youssef and Avolio (2007) after review of recent research, for example, found a 375:1 ratio of negative to positive research topics on human resources and organisational behaviour issues. Coined the 'deficit' model of research the focus has been on approaches and behaviours that have served to highlight stress, conflict, dysfunctional behaviour and attitudes, and counterproductive organisational structures and cultures. Luthans and Avolio (2009) suggest that the focus of this research so far can only equip organisations and their members with some survival skills that may help them sustain average performance at best. 
However, recently an alternative field of study aimed at examining the positive situations and aspects of human life has had growing influence in organisational studies. Positive organisational scholarship, as an alternative to the deficit model of research, is aimed at understanding positive human processes and workplace dynamics that aid in making life meaningful (Donaldson and Ko 2010). The aim is to build on and highlight that which is right in organisations and which may contribute to future workplaces. Positive organisational scholarship has drawn from the principles of positive psychology. Positive Psychology sought to redirect psychological research towards the "forgotten aims of psychology of encouraging healthy and happy people to become more productive and self actualising" (Seligman 2002, 82). Positive psychology, therefore, is an 'umbrella' term for the study of positive emotions, positive character traits, and enabling institutions. Positive psychology focuses on strengths that build human potential, rather than the traditional model based on weaknesses (Peterson and Seligman 2003).

Proponents of the positive psychology and positive organisational scholarship movements maintain that research findings from the positive perspective should supplement, not replace, what is known about stress and the detrimental aspects of work and life. The intent of positive psychology, and positive organisational behaviour, is to have a more complete and balanced understanding of the human experience - "the peaks, the valleys, and everything in between... it should include an understanding of suffering and happiness, as well as their interaction, and interventions that both relieve suffering and increase happiness - the two separable endeavours" are of equal value in research (Seligman et al. 2005, 430). As such the aim of positive psychology is to develop ways and means to help people experience worthy emotions like personal happiness, both within themselves and within the broader social context in which they work and live (Gavin and Mason 2004; Wright and Quick 2009 a,b).

\section{THE ROLE OF EMPLOYEE HAPPINESS [WELLBEING]}

'Happiness' is a lay construct. Although the term 'happiness' is derived from Aristotle's teachings of eudaimonia, the term 'happiness' when used is replete with personal meaning for each of us. Therefore in order to study the idea of 'happiness' more scientifically with more precise definition, scholars have tended recently to treat 'happiness' as 'wellbeing' (Hird 2003; Ryan and Deci 2008). Wellbeing is a broader construct than 'happiness' and includes wellbeing in terms of personal growth, purpose in life, positive relationships with others, and social contribution and integration (Eid and Larsen 2008; Keyes 1988; Ryff 1989; Ryff and Keys 1995; Diener, Suh, Lucas and Smith 1999; Keyes and Magyar-Moe 2003).

Although growth in the field of wellbeing also reflects larger societal trends concerning the value of the individual, combined with the importance of subjective views in evaluating life (Haybron 2006; Kashdan, Rose and Finchman 2004; Kashdan, Uswatte and Julian 2006; Fredrickson 2000) within the workplace, wellbeing is increasingly becoming an important issue as those organisations that recognise the role of wellbeing are found to have more "creative, effective and socially integrated workers" (Fredrickson 2003, 171).

Wellbeing at work has a long history - the 'happy' worker as a productive worker is not a new thesis. In fact the Hawthorne studies in the 1920s highlighted the role and contribution of happiness to productivity. Recent research has supported this hypothesis (Quick and Quick 2004; Wright and Cropanzano, 2004; 2007). For example, research investigating the connection between wellbeing and employee retention appear to be promising. Indeed Wright (2006; 2007) and Harter, Schmidt, and Hayes (2002; 2003) suggests that employee wellbeing may eventually prove to be a more robust predictor of whether employees decided to stay or leave their jobs than either job satisfaction or job commitment. Additionally, wellbeing has been related to improved physical health (Carver, Scheier, Segerstrom 2010), personal striving, coping with stress (Diener and Fujita 1995;, Emmons, 1992; Folkman 1997), and satisfaction with important other life domains (Diener, 2000). As Wright (2006) suggests "happiness quite isolated from productivity and job satisfaction measures could become a desired outcome for organisations in itself' (p.124).

The importance of wellbeing may also be crucial for organisational success in the near future. With estimates in New Zealand of over half a million workers at retirement age by 2011, and projections into well over 1 million workers in the next few decades (New Zealand Statistics, 2008), and with similar projections across Australia (Shacklock, Fulop and Hort 2007), America and the UK (Luthans et. al. 2007) organisations, in order to retain or develop some form of competitive advantage in the employee recruitment and retention stakes, may need to 
consider the value of wellbeing and happiness to employees. As Wright $(2006,120)$ suggests "an organisation that fosters wellbeing may create for itself a distinct competitive advantage in the looming competition for employees".

\section{EUDAIMONIC WELLBEING}

As stated, wellbeing includes wellbeing in terms of personal growth, purpose in life, and positive relationships with others. These have been conceptualised as the eudaimonic contributors to wellbeing (Ryff and Singer 2008; 1988, 2000; Spangler and Palrecha 2004). These are discussed further below.

\section{Purpose and meaning}

A large body of research indicates that having and working towards goals associated with meaning and value is associated with wellbeing (see Ryan and Deci 2001; Diener, Suh and Oishi 1997). Goals create connection and developmental opportunities. Moreover, the purist of goals in relation to wellbeing is enhanced when they are developed via self concordance, and autonomously. Goals that are poorly integrated to self, whose focus is not related to a psychological driver, convey less wellbeing effects, even if achieved (see Ryan and Deci 2001 for a review).

Spangler and Palrecha (2004) found that when one's core values and meaning were aligned eudaimonic wellbeing is enhanced. This alignment of purpose, goals and self reflects an interesting and growing aspect of wellbeing. Research is emerging in the way individuals find positive "meaning in life" (van Dierendonck and Krishna 2006, 238). Holding or having philosophical (or spiritual) beliefs on the "meaning of life" can aid eudaimonic wellbeing. The "sense of core purpose" (Folkman 1997, 1210) involves living out life in relation to core beliefs and values (van Dierendonck and Krishna 2006). Research to date suggests that those individuals that are the 'happiest' tend to have spiritual, philosophical or 'core meaning' beliefs that are reflected in their daily lives (Seligman 2005).

\section{Social connectedness}

Ryff and Singer (2000) discuss the value of social connectivity in wellbeing. They argue that "quality ties to others are universally endorsed as central to optimal living and wellbeing" (p.30). Specifically, quality ties that integrate one into one's community and enable the person to contribute to that community and as such to the social good of that community, aid wellbeing (Social Report 2006; Diener et al. 1997). Studies suggest that of all factors that influence happiness, relatedness is at or very near the top of the list (Diener and Seligman 2002; Argyle 1987) and an essential element for human flourishing (Berscheid 1994). Specific workplace research by Harter, Schmide and Keyes (2002: 2003) found social interaction to be an important element in job satisfaction. Similarly Keys and Magyar-Moe (2003) Kahn (2007) and Simon, Judge and Halvorsen-Ganepola (2010) confirmed the key role of social support in happiness, and found that work-related social support was a key factor in a person's general state of well being.

Gable, Impett, Reis and Asher (2004) examined how social connectedness through positive events created an additional benefit; connecting and discussing with other people positive events created a benefit over and above the positive event itself. Sharing and connecting with people regarding positive events, they found, built additional social resources, and strengthened relationships, an additional benefit for enhancing wellbeing and connectivity. Additionally, the notion of wellbeing building additional resources creates further impetus for aiding employee wellbeing.

\section{WELLBEING BROADENS AND BUILDS POSITIVE PSYCHOLOGICAL STATES}

Wellbeing has been found to aid positive emotions, broaden ranges of wellbeing cognitions and behaviour and build resources within the person and within the organisation (Sauter, 2010, Kok and Fredrickson in press, Fredrickson and Branigan 2006; Fredrickson 2000). The 'broaden' and 'build' research in wellbeing found that 'building' an employee's personal resources creates the capacity to psychologically grow, both on and off the job. As an added benefit, this sense of flourishing makes psychologically well people more proactive and less prone to 
stress related depressive symptoms (Ryff, Singer and Love 2004). The broaden model of wellbeing has been found to have a 'capitalisation' effect, in that positive wellbeing in one domain can aid wellbeing across other domains of an organisation and the individual's life domains (Gable, Impett, Reis and Asher 2004). Some research has also referred to this as the contagion process (Luthans et al 2007) in that the positive affect is transferred to others who were not party to the original positive event. Wright and Cropanzano $(2005 ; 2007)$ used the broaden and build model of wellbeing to support findings of the increased interactive nature and number of positive based employee behaviours and emotions.

\section{LIVEABILITY OF ENVIRONMENT AND WELLBEING}

Although wellbeing, as described above, relates to the individual, the environment within which we work and live more broadly has an impact on our ability to experience wellbeing (Ryan and Deci 2008). The "liveability" of the environment is viewed as a precondition to happiness and not all environmental conditions are conducive to wellbeing (The World Database of Happiness 2007). The liveability of our environment has many levels. For example, ecologists foresee liveability in the natural environment and describe it as pollution and degradation of nature; therefore they associate liveability of the environment with restoration. Sociologists refer to liveability as the quality of society as a whole, including social positions. Ryan and Deci (2008) referred to the work 'situation' as an 'environmental' condition within which wellbeing is promoted or impaired.

\section{NEW ZEALAND FARMING CASE}

In New Zealand, small and medium (SMEs) sized businesses are the majority (Cameron and Massey 1999). The farming sector, a subset of SMEs, is still a strong contributor to the New Zealand economy; it is a major employer (NZ Statistics 2008) and an under-studied and under-examined aspect of workplace wellbeing. When reviewing farming literature more widely, the predominant aspect of research on farming has focussed on how stressful work and isolated working conditions seem to be the norm (Kelly et al, 2010; Firth et al. 2007; Lobley et al. 2004; Midmore, Sherwood and Roughley 2001; Pretty and Ward 2001). In Australia for example, the Department of Primary Industries has recently set up support services to aid the wellbeing of those farmers who continue to face stressful drought conditions.

Moreover, some recent literature has suggested farming be viewed by understanding farmers' perceptions of their workplace. Shreck, Getz and Freenstra (2006) suggested that environmental sustainability should not be under estimated as a farming issue, as it has a role in creating meaning for farmers. This is supported by Harris and Pringle (2007) who suggest that for small business owners' work, life and meaning are intertwined. Toma and Mathijs (2007) further support the notion of meaning and farming choices and practices, though not implications for wellbeing. Alternatively, Koelle and Oettle (2003) concluded that farming had an emotional connection for farmers and that "it is time to take the emotional side of farming seriously" (p.8). However, there remains a lack of research on farmers' subjective experiences, its relationship to their wellbeing, and resultant workplace sustainability.

Specifically how purpose, meaning and connectivity can be developed in workplaces where isolation is the norm is not adequately assessed (Kossek et al 2006: Shayo, Olfman, Iriberri and Igbaria 2007). Moreover, the research on workplace happiness thus far has tended to minimise the impact of the 'environment', or 'situations' in which wellbeing is promoted, or impaired (Wright 2004; 2006), particularly aspects of a changed work environment.

This study will examine wellbeing - purpose and meaning, and social connectivity - in an isolated farming community near Cambridge, New Zealand and highlights how an improved work context (through the process of surrounding ecological restoration) created a conducive situation in which individual wellbeing thrived. Further, the broaden and build framework is used to explain how purpose and meaning created additional positive outcomes in terms of social connectedness and wellbeing.

\section{Maungatautari Mountain Ecological Reserve and surrounding Farmer Wellbeing}

Maungatautari Mountain is a volcanic cone located in the Waikato basin located in the North Island of New Zealand. The Maungatautari Ecological Island Trust (MEIT) commenced the physical construction of fencing for 
the entire $47 \mathrm{kms}$ of land surrounding Maungatautari Mountain, in order to lead a community project of ecological restoration of the mountain. At the time of the fence construction there were 21 farmers whose support was gained by MEIT before the project of ecological restoration could commence. The consent of the 21 farmers made the fence construction, and hence ecological preservation of Maungatautari Mountain, a practical option (MEIT 2005).

\section{METHOD}

\section{Sample}

All 21 farmers whose workplaces border Maungatautari Mountain participated in the study. Over a seven month period, the stories of farmers whose workplaces border the mainland island were collected.

\section{Procedure}

This study used storytelling to gain insight into farmers' experience of ecological preservation and the impact of this on their wellbeing. Storytelling allowed for further meanings and examples of "wellbeing" to be developed (Gold and Holman 2001; Walker 2004) and allowed for the different perspectives and interests of members of the farming community to be understood. Further this perspective argues that meaning is created jointly, in that the collection of stories allowed for a collective understanding of how the members of the farming "workplace community make sense of their experience" (Gabriel 2000, 87). Though some wellbeing researchers have measured day-to-day self reports on wellbeing (Stone et al. 1999), Ryff and Singer (2008: 1998) moreover, called for studies that acknowledge that events and circumstances must be understood in the context of the lives in which people are experiencing wellbeing and that recognise the contextual factors may change the meaning of events for different people.

The 21 farmers were given the overall aim of the research and asked to retell issues they had on the impact of the development of the Maungatautari ecological reserve and predator proof fence on their workplace wellbeing. The stories were taped, transcribed and sent back to the farmer for verification or changes. Data gained were content analysed and a thematic search undertaken.

Thematic analysis explored the main perspectives told by farmers (O'Brien 2005). Thematic analysis involved methodically reading the verbatim transcripts and segmenting and coding the text into categories that highlight relevant areas (Aronson 1994, Boyatzis 1998, O'Brien 2005).

An analysis of categories was undertaken, assessed, compared and interpreted for similarities and differences and then assigned to themes. These provided a framework to explain how farmers' wellbeing was affected by the predator proof fence and restoration process. Codes for wellbeing were generated using Ryff's (1989) analysis and categorisation of eudaimonic wellbeing - including meaning, purpose, and social connectivity. Farmers were allocated a nominal unique identifier, and were assigned a number from 1-21. QSR NVivo was used to facilitate the coding and analysis of information.

\section{RESULTS DISCUSSION}

All 21 stories demonstrated that the restoration process of Maungataturi Mountain had a positive impact on farmers' workplace and experience. Stories across the sample focussed on how the restoration process aided in enhancing personal meaning for farmers and this in turn aided in developing community relationships. Hence the lessening of isolation was via the restoration process, because this provided for a common, unifying and meaningful connection. As such, as stories progressed from initial resistance to the restoration process, a common theme was that the unifying connection (restoration) actually became personally significant and meaningful to farmers' wellbeing. The following are a selection of examples and excerpts from these stories that show a progression from (1) resistance to restoration, to (2) meaningfulness of the project to (3) social connectivity. These excerpts demonstrate how the meaning that developed from ecological restoration, created social connection, and how this enhanced wellbeing. That is, the restoration process had a broaden and building aspect to farmers wellbeing. 
The first set of analysis, demonstrates that ecological restoration was not a primary motivator for farmers initially. That is, the stories demonstrate a notable progression from initial uncertainty of the restoration process:

\section{Initial Reactions}

- $\quad$ (Story 5) “...my first impression.... what an insurmountable project, impossible to achieve...”

- $\quad$ (Story 8) “...crazy, impossible, unlikely to happen.... where do you start...”

- (Story 12) “..Thought it was an ambitious idea.... and wondered how much land I was going to lose...”

- $\quad$ (Story 14) “...At first I thought there'd be about a 50\% chance that it would go ahead..."

- (Story 15) “... (impression of) the project was that it was impossible and that it could not be done..."

As stories progressed, and farmers began to recall the actual process of restoration, the stories began to tell of more enduring changes or evidence of eudaimonic wellbeing in terms of purpose and meaning. Farmers demonstrated that the value of restoration began to have some significance for them: The following excerpts continue on from above:

Movement to Purpose and Meaning:

- $\quad$ (Story 5 continues ) “...It would also be great for the neighbourhood, great for ecology and great for the mountain... There were so many good reasons for us to be part of it..."

- (Story 10 continues) "...there is a sense now we are stewards of this mountain..."

- $\quad$ (Story 12 continues) "......we also believe that we are caretakers of the land and we try to improve and add our own little bits to it as we go along... (continues again).......It is good to be able to leave your mark and then perhaps somewhere along the line the grandkids will be able to say, "hey grand dad was involved in this".

- $\quad$ (Story 15 continues) “...involved for future generations but we will be able to see if for ourselves...”

In examining the development in stories, significantly stories mentioned how the meaning of restoration resulted in greater social connections with other farmers around the Mountain. That is the stories told of improvements (or building of) social connectivity around Maungatautari Mountain. This is discussed in more detail in the following section.

\section{Social Connectivity}

- $\quad$ (Story 5 Continues) “....because they were the next three farms that were going to be hit... We took them out, (Communications person) was with us... we took them down to the southern enclosure and showed them what had been done, how it would look at the finish and then we had lunch at Out in the Styx \{restaurant\}....it wasn't really a big job, but the farmers' got to see what the end would look like ..."

- $\quad$ (Story 8 continues) “... We did not know who owned what, and there are a number of landowners around the mountain...now (name) is involved in planting groups from all over the mountain..."

- (Story 10 continues) “...At the completion of the northern enclosure one of the special days for me was the feeling of aroha ${ }^{1}$ when the circle around the mountain was completed... Even though it was a logistical nightmare ... it seemed as though the heavens were for it because the rain stopped, the sun came out, and there was a wonderful feeling of the whole community coming together.....It was obvious that many other people in the community had felt the same aroha because of all the e-mails we got afterwards..."

- (Story 12 continues) “.......We are not great meeting attending sort of people.... but now we have people call in here all the time... (Continues)... people from all round... came for that common cause."

- $\quad$ (Story 15 continues) “...we have been involved on a number of occasions; in providing food and drink ... This would not have happened if it were not for the project... My attitude is that on these occasions we provide the food and drink which is a "feel good" opportunity...."

\footnotetext{
${ }^{1}$ Maori word suggesting compassion, tenderness, sustaining love.
} 


\section{DISCUSSION}

A changed or improved workplace created and aided conditions within which wellbeing was enhanced. Positive changes in terms of purpose, meaning and wellbeing were demonstrated via the above stories (see the development in stories 5,12,15 - from initial reaction to purpose, values and meaning). For example initial permission was not based on valuing restoration, but on the belief it probably would not go ahead. (for example story 5 - an insurmountable project). Whereas, as the process of restoration developed, goals moved towards 'meaningfulness' (for example story 12 - we see ourselves as caretakers of the land).

The changed work environment also aided social connectivity and built social relations and cohesion in a work environment that was isolated (story 12 and 15 social connectivity). The common meaning and purpose behind the initial project created a building foundation for workplace relationships that were initially isolated and fragmented, to be broadened and enacted at the community level (for example story 8,10 .) Thus social connectivity that sustained participation in the activity has a positive consequence on wellbeing.

The development of social connectivity was initially founded around the development of a common purpose (restoration), however some of these relationships became key to, or instrumental in, aiding the 'mission' of the project to its fruition (example story 5, progression from initial reaction, purposes to social connectivity particularly in social connectivity - "we showed them what had been done"). That is, the social connectivity became 'instrumental' in developing the project to completion, suggesting that the social connectivity had not only a 'broaden' but 'build' aspect to it.

The study also illuminates another interesting aspect. Though most workplaces will not be effected by ecological restoration, this study does demonstrate how the impact of a changed, positive work environment, or the 'liveability of (work) environments', aided in creating meaning and purpose, and this can have a broaden and build aspect for an individual's wellbeing.

\section{LIMITATIONS}

Happiness and wellbeing are difficult constructs to not only define, but to isolate and research (Kahneman 1999; Larsen and Fredrickson 1999). However, the stories and restoration case study, do provide initial evidence of positive wellbeing as a consequence of a changed work environment - one that aided meaning, purpose and social connection for those affected. We encourage further research that investigates the positive aspects of workplaces and particularly how positive workplaces can aid wellbeing.

\section{CONCLUSIONS}

Happiness and wellbeing is a 'holistic ideal'. It not only speaks of one's own subjective views and evaluations, but the social and contextual aspects of work and life. We spend a considerable amount of our lives working and as such happiness and wellbeing at work is essential (Wright 2006).

This study supports Gavin and Mason's (2004) view that Aristotle's argument must now be expanded to include: "In order to achieve the good life people must work in good organisations if they are to be truly happy: (pp 388). The above study demonstrates the positive consequences of 'good work places' on wellbeing, and additionally, the study highlights how wellbeing can have a broaden and build aspect to it, creating additional benefits.

The findings also add to the premise that the objectives for human resources may be to move from accommodating employees' needs to leveraging employee potential by investigating the numerous complexities involved in the developing of future employment relationships - including focusing on supportive environments that foster wellbeing. Finally, as Wright $(2004 ; 2006)$ suggest, if we are to create and maintain healthier, happier workplaces, human resource professionals are well advised to place more emphasis on the contributions of positive psychology. 


\section{AUTHOR INFORMATION}

Maree Roche is a Senior Academic Staff Member within the School of Business, WINTEC, New Zealand. Maree teaches and researches in Leadership and Organisational Behaviour. In particular Maree's research interests include an emphasis on Positive Organisational Behaviour which focuses on the positive aspects of work and life.

Carollyn Rolley is a Senior Academic Staff Member within the School of Business, WINTEC, New Zealand. Carollyn teaches on a range of subjects within Administration Studies. Carolyn maintains an active interest and involvement in the ecological restoration of Maungataturi Mountain.

\section{REFERENCES}

1. $\quad$ Argyle, M. (1987). The psychology of happiness. London: Methuen.

2. Aronson, J. (1994). A pragmatic view of thematic analysis in The Qualitative Report 2, viewed 14 September 2006, http://nova.edu/ssss/Qr/BackIssues/QR2-1/aronson.html

3. Berscheid, E. (1994). Interpersonal relationships. Annual Review of Psychology 45, 79-129.

4. Blatt, R., and Camden, C (2007). Positive relationships and cultivating community. In exploring positive relationships at work: Building a theoretical and research foundation, eds J. Dutton and B. Ragins, 189207. London UK: Lawrence Erlbaum Associates

5. Boyatzis, R.E. (1998). Transforming qualitative information: Thematic analysis and code development. London: Sage Publications.

6. Cameron, K.S., Dutton J.E. Quinn, R.E. (2003). Positive organisational scholarship: Foundations of a new discipline. San Francisco: Berrett-Koehler.

7. Cameron, A., Massey, C. (1999). Small and medium sized enterprises. A New Zealand perspective. Longman, New Zealand.

8. Cantor, N. and Fleeson, J. (1991). Life tasks and self regulatory processes. Advances in Motivation and Achievement. 7,327-369.

9. $\quad$ Carver, C.S, Scheier, M.F. \& Segerstrom S.C. (2010) Optimism. Clinical Psychology Review. 30 (7) p. 879-889.

10. Donaldson, S and Ko, L. (2010). Positive organizational psychology, behaviour and scholarship: A review of the emerging literature and evidence base. Journal of Positive Psychology. 5,(3) pp 177-191.

11. Department of Primary Industries. (2007). Drought assistance initiatives viewed 16 January 2008 from www.dpi.vic.govt.au

12. Devettere, R. J. (2002). Introduction to virtue ethics: Insights of the ancient Greeks. Washington D.C.: Georgetown University Press.

13. Diener, E. and Seligman, M. (2002). Very happy people. Psychological Science, 13, 81-84.

14. Diener, E. and Lucas, R.E. (2000). Subjective emotional well-being. In M. Lewis and J. Haviland-Jones, eds. Handbook of Emotions, $2^{\text {nd }}$ edn. Guilford, New York, 325-337.

15. Diener, E., Suh, E. Lucas, E. and Smith, H. (1995). Resources, personal striving, and subjective wellbeing: A monothetic and idiographic approach. Journal of Personality and Social Psychology 68, 926-935.

16. Diener, E., Suh, E.M. Lucas R.E and Smith, H.E. (1999). Subjective well-being: Three decades of progress. Psychological Bulletin 125(22), 276-302.

17. Diener, E., Suh, E and Oishi, S. (1997). Recent findings on subjective well-being. Indian Journal of Clinical Psychology 24, 25-41.

18. Eaton, S. (2003). If you can use them: Flexibility policies, organizational commitment, and perceived performance. Industrial Relations, 42, 145-167.

19. Eid, M. and Larsen, S.J. (2008). The science of subjective wellbeing. Guilford Publications. New York.

20. Emmons, R.A. (1992). Abstract versus concrete goals: Personal striving level, physical illness and psychological wellbeing. Journal of Personality and Social Psychology 62, 292-300.

21. Firth, H.M., Williams, S. M, Herbison, S. and McGee, R.O. (2007). Stress in New Zealand farmers. Stress and Health 23(1), 51-63.

22. Folkman, S. (1997). Positive psychological states and coping with severe stress. Social Science Medicine 45(8), 1207-1221. 
23. Fredrickson, B.L. (2000). Cultivating positive emotions to optimize well-being and health. Prevention and Treatment 3,1-25.

24. Fredrickson, B.L. (2003). Positive emotions and upwards spirals in organisations. In Foundations of a New Discipline. Eds K.S. Cameron, J.E. Dutton, and R.E. Quinn. San Francisco: Berrett-Koehler.

25. Fredrickson, B. L. and Branigan, C. (2006). Positive emotions broaden the scope of attention and thoughtactions repertories. Cognition and Emotion 12(3), 191-220.

26. Fredrickson, B.L., Tugade M.M., Waugh, C.E and Larkin, G.R. (2003). What good are positive emotions in crisis? A prospective study of resilience and emotions following the terrorist attacks on the United States on September 11, 2001. Journal of Personality and Applied Psychology 84, 365-376.

27. Gavin, J. and Mason., R. (2004). The virtuous organization: The value of Happiness in the workplace. Organizational Dynamics 6(7), 384-395.

28. Gable, S., E. Impett, H. Reis and Asher, E., (2004). What do you do when things go right? The intrapersonal and interpersonal benefits of sharing positive events. Journal of Personality and Social Psychology 87(2), 228-245.

29. Gabriel, Y. (2000). Storytelling in organisations - Facts, fictions and fantasies. Oxford UK: Oxford University Press.

30. Haar, J. M. (2006). The downside of coping: work-family conflict, employee burnout and the moderating effects of coping strategies. Journal of Management and Organization, 2(12), 146-159.

31. Harris, C and Pringle, J. (2007). Work-Life Balance: who is the target for this Silver Bullet? Paper presented at Australian Centre for Research in Employment and Work, Melbourne, Dec. 2007.

Harter, J., Schmidt, F. and Hayes, T. (2002). Business-unit-level relationship between employee satisfaction, employee engagement, and business outcomes: A meta-analysis. Journal of Applied Psychology 87, 268-279.

32. Harter, J., Schmidt, F and Hayes, T. (2003). Wellbeing in the workplace and its relationship to business outcomes: A review of the Gallup studies. In Flourishing: Positive psychology and the life well lived, eds C. Keyes and J. Haidt, 181-196. Oxford, UK: Oxford University Press.

33. Haybron, D. (2007). Life satisfaction, ethical reflection, and the science of happiness. Journal of Happiness Studies 8(1), 99-108.

34. Hird, S. (2003). What is wellbeing? A brief review of the current literature and concepts. Social Psychology Quarterly 61(2), 121-140.

35. House, J. and Khan, R. (1985). Measures and concepts of social support. In Social support and health, eds S. Cohen and S.L. Syme, 83-108. Olando: Academic Press.

36. Kahn, W. (2007). Meaningful connections: Positive relationships and attachment at work. In Exploring Positive Relationships at Work: Building a Theoretical and Research Foundation, eds J. Dutton and B. Ragins, 189-207. London UK: Lawrence Erlbaum Associates.

37. Kahneman, D. (1999). Objective happiness in well-being The foundations of hedonic psychology eds D. Kahneman, E. Diener, and R Schwarz. New York: Russell Sage.

38. Kashdan, T.B. (2004). The assessment of subjective wellbeing (issues raised by the Oxford Happiness Questionnaire). Personality and Individual Differences 36, 1225-1232.

39. Kashdan, T.B., Rose, P and Finchman, F.D. (2004). Curiosity and exploration. Facilitating positive subjective experiences and personal growth opportunities. Journal of Personality Assessment 82(3), 294305 .

40. Kashdan, T.B., Uswatte, G. and Julian. T. (2006). Gratitude and hedonic and eudaimonic well-being in Vietnam war veterans. Behaviour Research and Therapy 44(2), 177-199.

41. Kelly B.J.,Stain, H. J., Coleman, C., Perkins, D., Fragar, L, J. Fuller, Lewin T.J., Lyle, D., Carr, V.J., Wilson, J.M. and Beard, J R. (2010). Mental health and well-being within rural communities: The Australian Rural Mental Health Study. Australian Journal of Rural Health Volume 18, 1, pp 16-24, February 2010

42. Keys, C . (1988). Social wellbeing. Social Psychology Quarterly 61, 121-140.

43. Keys, C., and Magyar-Moe, J. (2003). Flourishing: Positive Psychology and the life well-lived. Washington D.C.: American Psychological Association.

44. Koelle, B.R. and Oettle, N.M. (2003). Myths, legends and nature. Farming as an emotional enterprise. Environmental Monitoring Group, London. 
45. Kok, B. E. and Fredrickson, B. L. (in press). Upward spirals of the heart. Autonomic flexibility, as indexed by vagal tone, reciprocally and prospectively predicts positive emotions and social connectedness.

Biological Psychology.

46. Kossek, E. E., and Ozeki. C. (1999). Bridging the work-family policy and productivity gap. International Journal of Community, Work and Family. 2. 7-32.

47. Kossek, E. E., Lautsch, B. A., and Eaton, S. C. (2006). Telecommuting, control, and boundary management: Correlates of policy use and practice, job control and work-family effectiveness. Journal of Vocational Behavior. 68. 347-367.

48. Larsen, R. and Fredrickson, B. (1999). Measurement issues in emotion research? In Well-Being The Foundations of Hedonic Psychology eds D. Kahneman, E. Diener, and R Schwarz, New York: Russell Sage.

49. Lobley, M.,. Johnson, G., Reed, M., Winter, M. and Little, L. (2004). Rural stress review. Final Report, Centre for Rural Research, Exeter: University of Exeter.

50. Luthans, F. and Avolio, B. (2009). The point of positive organisational behaviour. Journal of Organizational Behavior Special Issue: The Emerging Positive Agenda Volume 30,2, pages 291-307, February 2009

51. Luthans, F., Youssef, C, and,Avolio. B. (2007). Psychological Capital: Developing the human competitive edge. Oxford: Oxford University Press.

52. Mark, J.E. (2006). Organic Farming. Environmental Magazine 12(2), 20-23.

53. Markus, H.R. and Kitayama. S. (1991). Culture and the self: Implications for cognition, emotion, and motivation. Psychological Review 98(2), 224-253.

54. MEIT (2005). Community Newsletters, viewed 6 May 2005, http://www.maungatrust.org

55. Midmore, P., A. Sherwood, and. Roughley, G. (2001). Policy reform and the sustainability of farming in the uplands of the United Kingdom, Conflicts between environment and social support. Journal of Environmental Policy and Planning 3(1), 43-63.

56. New Zealand Statistic. (2008). Population Trends 2007-2050, viewed 23 September 2008, http://www.nzstatisic.govt.nz

57. New Zealand Statistic. (2008). Farming and agriculture, GDP and employment tables, viewed 18 November 2008, http://www.nzstatisic.govt.nz

58. O’Brien, E.A. (2005). Publics and woodlands in England, well-being, local identity, social learning, conflict and management. Social Research Group, Forest Research 78(4), 321-336.

59. Peterson, C.M., and Seligman. M.E.P (2003). Positive organizational studies, Lessons from positive psychology. In Foundations of a New Discipline, eds K.S., Cameron, J.E. Dutton, and R.E. Quinn. San Francisco: Berrett-Koehler.

60. Pretty, J. and Ward, H. (2001). Social capital and the environment, World Development, University of Essex, 29(2), 209-227.

61. Quick, J,C. and Quick. J.D. (2004). Healthy, happy, productive work. Organizational Dynamics 32, 329337.

62. Ryan, R. and Deci. E.L (2001). On happiness and human potentials: A review of research on hedonic and eudaimonic wellbeing. Annual Review of Psychology 52, 141-166.

63. Ryan, R. M. \& Deci, E. L. (2008). Facilitating optimal motivation and psychological well-being across life's domains. Canadian Psychology, 49, 14-23.

64. Ryff, C.D., (1989). Happiness Is Everything, or Is It? Explorations on the Meaning of Psychological WellBeing 57 (6),1069-1081.

65. Ryff, C.D. and Singer. B. (1998). The contours of positive human health. Psychological Inquiry 9(1),1-28.

66. Ryff, C.D. (1989). Beyond Ponce de Leon and life satisfaction: New directions in quest of successful aging. International Journal of Behavioural Development, 69,35-55.

67. Ryff, C.D. and C.M. Keys. (1995). The structure of psychological wellbeing revisited. Journal of Personality and Social Psychology 69,719-727.

68. Ryff, C.D. and Singer. B. (2000). Interpersonal flourishing: A Positive health agenda for the new millennium. Personality and Social Psychology Review 4(1),30-44.

69. Ryff, C.D. and Singer.B. (2008). Know thyself and become what your are: A Eudaimonic approach to psychological wellbeing. Journal of Happiness Studies 9(1),13-39. 
70. Ryff, C.D., B. Singer and G.D. Love. (2004). Positive health: connecting well-being with biology. The Royal Society Biological Sciences 35(9),1383-1394.

71. Sauter, K. (2010). More Than Happy: The Need for Disentangling Positive Emotions Current Directions in Psychological Science,19(1),36-40.

72. Seligman, M.E.P. (1999). What you can change and what you can't, From the president's address. American Psychologist, 54(7), 559-562.

73. Seligman, M.E.P., Steen, T, and Peterson, C. (2005). Empirical validation of interventions: Positive psychology progress. American Psychologist 60(5),410-421.

74. Shacklock, K., L. Fulop, and Hort, L. (2007). Managing older worker exit and re-entry practices: a 'revolving door'? Asia Pacific Journal of Human Resources 45 (2),151-167.

75. Shayo, C., Olfman, L., A. Iriberri, and M. Igbaria. (2007). The virtual society: Its driving forces, arrangements, practices and implications. In Psychology and the Internet: Interpersonal and intrapersonal implications. New York: Sage Publications.

76. Shreck, A., Getz, C. and Feenstra, G. (2006). Humanities, Social Sciences and Law', Agriculture and human values, 23(4), 439-451.

77. Simon, L. S., Judge, T. A., \& Halvorsen-Ganepola, M. D .K . (2010). In good company? A multi-study, multi-level investigation of the effects of coworker relationships on employee well-being. Journal of Vocational Behaviour 76, 534-546

78. Social Report (2006). Quality of life in New Zealand Cities. Ministry of Social and Economic Development, New Zealand.

79. Spangler, W.D. and Palrecha.R. (2004). The relative contributions of extraversion, neuroticism, and personal strivings to happiness. Personality and Individual Differences 37(6), 1193-1203.

80. Stone, A.A., J.S. Turkkan, C.A. Bachrach, J.B. Jobe, H.S. Kurtzman and V.S. Cain. (1999). The science of self report: Implications for research and practice. Mahwah, New Jersey: Lawrence Erlbaum.

81. Van Dierendonck, D. and Krishna, M. (2006). Some thoughts on spirituality and eudaimonic well-being. Mental Health, Religion and Culture, 9(3), 227-238.

82. Veenhoven, R. (2004). Subjective measures of well-being. World Institute for Development Economics Research, Discussion Paper no. 2004/07.

83. Walker, A. (2004). I know what the earth says. Southern Cultures 10(1), 5-24.

84. World Database of Happiness. Correlational Findings. Viewed 17 July 2007 http://worlddatabaseofhappiness.eur.nl

85. Wright, T. and Cropanzano. R. (2005). The role of psychological wellbeing in job performance: A fresh look at an age-old quest. Organizational Dynamics 33(4), 338-351.

86. Wright, T. and Cropanzano. R. (2007). The happy/productive worker thesis revisited. Research in Personnel and Human Resource Management 26, 269-307.

87. Wright, T. (2004). The role of 'Happiness' in organizational research: past, present and future directions. Research in Occupational Stress and Well Being 4(3), 221-264.

88. Wright, T. (2006). To be or not to be [happy]: The role of employee well-being. The Academy of Management Perspective 20(3),118-125.

89. Wright, T. A. \& Quick, J. C. 2009a. The emerging positive agenda in organizations: Greater than a trickle, but not yet a deluge. Journal of Organizational Behaviour. 30, 147-159.

90. Wright, T. A., \& Quick, J.C. 2009b. The role of positive-based research in building the science of organizational behavior. Journal of Organizational Behaviour, 30, 329-336. 


\section{NOTES}

